\title{
The Use of Cardiac Resynchronization Therapy in Cancer Patients with Heart Failure
}

\author{
Fadol $\mathrm{AP}^{{ }_{1}}$, Mouhayar $\mathrm{E}^{2}$ and Reyes-Gibby $\mathrm{CC}^{3}$ \\ ${ }^{1}$ Department of Nursing, The University of Texas MD Anderson Cancer Center, Houston, USA \\ ${ }^{2}$ Department of Cardiology, The University of Texas MD Anderson Cancer Center, Houston, USA \\ ${ }^{3}$ Department of Emergency Medicine, The University of Texas MD Anderson Cancer Center, Houston, USA
}

${ }^{*}$ Corresponding author: Fadol AP, Department of Nursing, The University of Texas MD Anderson Cancer Center, 1515 Holcombe Blvd., Unit 0456, Houston, TX 77030, USA, Tel: (713) 792-8397, Fax: (713) 563-1349, E-mail: afadol@mdanderson.org

Citation: Fadol AP, Mouhayar E, Reyes-Gibby CC (2017) The Use of Cardiac Resynchronization Therapy in Cancer Patients with Heart Failure. J Clin Exp Res Cardiol 3(1): 105

Received Date: December 14, 2016 Accepted Date: April 26, 2017 Published Date: April 27, 2017

\begin{abstract}
Objectives: Investigate the use of cardiac resynchronization therapy (CRT) in cancer patients with heart failure (HF); assess factors associated with ischemic and non-ischemic HF.

Background: Many newer cancer therapies are cardiotoxic; thus, the incidence of HF has been increasing in this high-risk patient population. CRT has beneficial effects on morbidity, mortality, and left ventricular function in patients with non-ischemic cardiomyopathy, yet cancer patients and survivors who develop severe HF and are eligible for CRT often does not receive it.

Methods: Review of 2 years of echocardiography and electrocardiography data from cancer patients.

Results: Of 272 patients meeting inclusion criteria for CRT placement (LVEF $\leq 35 \%$, QRS duration $\geq 120 \mathrm{~ms}$ ), 131 (48.2\%) had HF with ischemic etiology and 141 (51.8\%) had HF with non-ischemic etiology. Most patients had solid tumors, including breast, lung, sarcoma, and lymphoma $(73.2 \%, \mathrm{n}=199)$. Only $21.3 \%(58 / 272 ; 27$ ischemic; 31 non-ischemic) underwent CRT placement, who were mostly women and those with solid tumors. Non-ischemic HF was significantly associated with younger age $(<65$ years) (OR=0.91; 95\% CI=0.87-0.95) and female sex $(\mathrm{OR}=2.5 ; 95 \% \mathrm{CI}=1.1-6.0)$. As expected, ischemic HF was significantly associated with history of myocardial infarction, diabetes, and cardiovascular disease.

Conclusion: CRT is underutilized in cancer patients with HF. Most of the cancer patients who did not receive CRT had non-ischemic HF secondary to chemotherapy. CRT may be less utilized in those patients due to shortened life expectancy, yet evidence suggests that CRT has beneficial effects on morbidity, mortality, and left ventricular function. Its use may improve patient quality of life and allow
\end{abstract} oncologists to continue cancer treatments that could prolong survival.

\section{Condensed Abstract}

The advent of new cancer therapies has led to an increase in the number of long-term cancer survivors. However, many of these therapies are cardiotoxic, and thus the incidence of heart failure (HF) has been increasing in this high-risk patient population. Despite the known benefits of cardiac resynchronization therapy (CRT), a substantial number of cancer patients and survivors who develop severe HF fail to receive indicated therapies such as CRT, even when they meet eligibility criteria. Optimization of recommended therapies such as CRT may improve patient quality of life and allow oncologists to continue cancer treatments that could prolong survival.

Keywords: Cancer; Heart Failure; Cardiac Resynchronization Therapy; Non-Ischemic Etiology; Chemotherapy-Induced Cardiomyopathy; Left Ventricular Ejection Fraction; Myocardial Infarction; Coronary Artery Disease; Diabetes Mellitus; Dyslipidemia

List of Abbreviations: ACEI: Angiotensin Converting Enzyme Inhibitor; CI: Confidence Interval; CRT: Cardiac Resynchronization Therapy; HF: Heart Failure; LVEF: Left Ventricular Ejection Fraction; OR: Odds Ratio; SD: Standard Deviation

\section{Introduction}

The advent of new cancer therapies has brought about an increase in the number of long-term cancer survivors. However, many of these newer therapies are cardiotoxic, and thus the incidence of heart failure (HF) has been increasing in this high-risk patient population. Cardiac resynchronization therapy (CRT) is one of the most significant advances in the treatment of patients experiencing severe HF with impaired ejection fraction and ventricular conduction disturbances [1-2]. The biventricular pacing induced by CRT has been shown to restore left ventricular synchrony, resulting in improved health outcomes [1,3-5]. 
Despite the known benefits of CRT for patients who meet criteria for placement, information about the use of this technology in cancer patients and cancer survivors with severe HF is limited. Because the ultimate goal in treating patients with cancer is to cure the disease, the adverse cardiac effects of treatment are often overlooked. For cancer survivors, ongoing care focuses mostly on intermediate and long-term monitoring for cancer recurrence, rather than on long-term monitoring for adverse effects from cancer treatment, such as cardiomyopathy and HF. As a consequence, a substantial number of cancer patients and survivors who develop severe HF fail to receive indicated therapies such as CRT, even when they meet eligibility criteria.

\section{Heart Failure Etiology}

HF may be of ischemic or non-ischemic etiology. In HF with ischemic etiology, ventricular dysfunction is a consequence of myocardial ischemia and infarction related to coronary atherosclerosis, manifested by a significant narrowing or occlusion of the coronary arteries noted on cardiac catheterization. Conversely, in non-ischemic cardiomyopathy, the weakened heart muscle can result from toxic injury (chemotherapeutic agents), infection, immunological abnormalities, or genetic factors. A significant proportion of patients with non-ischemic cardiomyopathy have idiopathic dilated cardiomyopathy, the cause of which has not been established and which is likely to be multifactorial, potentially including occult viral myocarditis, abnormalities of the immune system, infiltrative myocardial disease, or genetic factors. Oftentimes, determining non-ischemic cardiomyopathy as the exact etiology is made difficult by heterogeneity in definitions and diagnostic criteria. Many epidemiological and clinical studies simply classify patients as having non-ischemic cardiomyopathy if heart failure is present and there is no clinical or electrocardiographic evidence of coronary disease. In the cancer population, chemotherapy-induced cardiomyopathy is usually of non-ischemic etiology. A sub-analysis from a randomized clinical trial of patients with HF suggests that CRT has greater beneficial effects on morbidity, mortality, and left ventricular function in patients with non-ischemic cardiomyopathy [6]. Nonetheless, clinical guidelines for CRT use in the management of these patients are lacking.

\section{Antineoplastic Agents and Heart Failure}

A wide variety of antineoplastic agents can cause unintended consequences on to the cardiovascular system, leading to heart failure [7-11]. Given the high prevalence of cardiovascular disease and associated risk factors in the general population, patients may already have compromised cardiac function at the time of cancer diagnosis and before starting chemotherapy [12,13]. Furthermore, multiple risk factors such as hypertension, obesity, dyslipidemia, and metabolic syndrome can compromise the cardiovascular reserve and increase the likelihood of subsequent cardio-toxicity leading to HF [14].

Anthracyclines are the most frequently cited and well-studied class of cardiotoxic anticancer agents, and their use is limited by cumulative, dose-dependent toxicity [15-16]. Retrospective analyses from clinical trials in adults suggest that the incidence of HF due to doxorubicin was $1.7 \%$ at a cumulative dose of $300 \mathrm{mg} / \mathrm{m}^{2}, 4.7 \%$ at $400 \mathrm{mg} / \mathrm{m}^{2}, 15.7 \%$ at $500 \mathrm{mg} / \mathrm{m}^{2}$, and $48 \%$ at $650 \mathrm{mg} / \mathrm{m}^{2}$ [15].

Trastuzumab, a humanized anti-ErbB2 monoclonal antibody used in the treatment of breast cancer and metastatic human epidermal growth factor receptor 2 (HER2)-positive gastric cancer, also is known for increased risk of cardio-toxicity, particularly when used with concomitant or sequential anthracyclines chemotherapy [17-21]. In one of the first clinical trials using trastuzumab for metastatic breast cancer, cardiotoxicity was noted in $27 \%$ of patients receiving trastuzumab concurrently with anthracyclines therapy and in $13 \%$ of patients receiving paclitaxel and trastuzumab [17]. Other agents that may cause heart failure in cancer patients include traditional chemotherapeutic agents such as cyclophosphamide, and docetaxel; and angio-genesis inhibitors, including bevacizumab and sunitinib [22-24].

In this study, we investigated CRT use in cancer patients with HF at our institution, a tertiary cancer center. We also assessed factors associated with the HF etiology, either ischemic or non-ischemic. The findings from this study have immense clinical significance. Optimization of recommended therapies such as CRT may improve patient quality of life and allow oncologists to continue cancer treatments that could prolong survival.

\section{Methods}

In this retrospective study, we reviewed echocardiography and electrocardiography data from patients with cancer who were seen in the Department of Cardiology at The University of Texas MD Anderson Cancer Center in Houston, Texas. Eligibility criteria were:

1)An echocardiogram performed between July 1, 2010, and June 30, 2012

2)A left ventricular ejection fraction (LVEF) of $\leq 35 \%$, as measured by the biplane method of disks (modified Simpson's).

3)QRS duration of $>120 \mathrm{~ms}$.

The MD Anderson Institutional Review Board approved the study. A waiver of informed consent was granted, given the retrospective design of the study. Materials described in the manuscript, including de-identified raw data, are stored in a password-protected database in the MD Anderson Department of Nursing. Materials can be made available for noncommercial purposes without breaching participant confidentiality. 
Prior to data collection, to ensure data quality and consistency, the primary investigator (APF) provided orientation and extensive training to the data abstractors. The data abstractors remained blind to the study questions to minimize review bias. To validate the proficiency of the data abstractors, a pilot data collection from $10 \%(\mathrm{n}=27)$ of the sample patient records was collected separately by the principal investigator and data abstractors and compared for consistency. Variables for which there was more than a $2 \%$ discrepancy between data abstractors were reassessed, and all data discrepancies were resolved jointly by the principal investigator and the data abstractor.

\section{Study Variables}

Sociodemographic data extracted were age, sex, and ethnicity. Electronic medical charts were reviewed for HF etiology (ischemic or non-ischemic), cardiac risk factors (hypertension, diabetes mellitus, dyslipidemia, coronary artery disease, myocardial infarction, family history of heart disease, and alcohol and tobacco use), LVEF, QRS duration, and cardiac medications (angiotensin converting enzyme inhibitors [ACEIs], angiotensin receptor blockers [patients who were intolerant to ACEIs], and beta-blockers). The etiology of left ventricular dysfunction was verified with a myocardial perfusion stress test or a left heart catheterization and confirmed as either ischemic or non-ischemic. For purposes of this study, the diagnostic etiology of non-ischemic cardiomyopathy was established by a negative myocardial perfusion stress test or left heart catheterization.

\section{Data Analyses}

Descriptive statistics were utilized to describe the study population. To examine the prevalence of type of HF (ischemic/nonischemic) in this study population, proportions and $95 \%$ binomial exact confidence limits for each type were calculated. Clinical and demographic characteristics were compared by type of HF, using the Wilcoxon rank-sum test, chi-squared test, or Fisher's exact test, depending on the distribution of the data. Univariate and multivariate logistic regression analyses were used to estimate the strength of association with HF etiology for the variables. Factors found to be significant $(\mathrm{p}<0.20)$ in the univariate analysis were included in the multivariate model; a $\mathrm{p}$ value of 0.20 was used as the cutoff because a more traditional value $(\mathrm{p}<0.05)$ often does not identify variables known to be important. Further variable selection in the multivariate model was conducted using backward elimination. To obtain the most parsimonious model, only variables with $\mathrm{p}$ values $<0.05$ were included in the final model. All statistical analyses were performed using SPSS software (SPSS Inc., Chicago, IL). All of the statistical tests were two-sided.

\section{Results}

\section{Patient Characteristics}

Of the 24,879 cancer patients with echocardiographic studies performed during the specified time period, 272 patients met inclusion criteria for CRT placement (LVEF $\leq 35 \%$ and QRS $>120 \mathrm{~ms}$ ). Of these patients, $58(21.3 \%)$ had CRT implantation, and of those, 27 (46.6\%) had ischemic etiology and 31 (53.4\%) had non-ischemic etiology.

The mean age of the subjects was 67.1 years (range 23-92 years); most were white (71.0\%) and male (65.1\%). Most had solid tumors (73.2\%, $\mathrm{n}=199)$, including breast, lung, sarcomas, and lymphoma; 70 (25.7\%) had liquid tumors, such as leukemia. Anticancer therapies with known cardiotoxicity used in the treatment of these patients included doxorubicin in 25 patients (9.2\%), trastuzumab in 7 patients $(2.6 \%)$, combination therapy (chemotherapy and radiation) in 44 patients (16.2\%), and mediastinal radiation in 41 patients $(15.1 \%)$.

In addition to cancer and HF, patients in this study had multiple comorbid conditions, including hypertension $(73.5 \%$, $\mathrm{n}=200)$, dyslipidemia $(61.8 \%, \mathrm{n}=168)$, coronary artery disease $(54.8 \%, \mathrm{n}=149)$, and diabetes mellitus $(37.9 \%$, $\mathrm{n}=103)$. Patients taking HF medications included $90.8 \%(\mathrm{n}=247)$ on beta-blockers, $50.0 \%(\mathrm{n}=136)$ on ACEIs, and $14.3 \%(\mathrm{n}=39)$ on angiotensin receptor blockers.

\section{Ischemic versus Non-Ischemic Heart Failure}

Table 1 compares the sociodemographic and clinical characteristics of patients with ischemic versus non-ischemic HF. Of the 272 patients, 131 (48.2\%) had HF with ischemic etiology and 141 (51.8\%) had HF with non-ischemic etiology. Patients with ischemic HF were mostly male $(77.9 \%$ vs. $53.2 \%$; $<0.001)$ and were more likely to have had a history of coronary artery disease ( $<<0.001)$, diabetes mellitus $(p=0.001)$, dyslipidemia $(p<0.001)$, myocardial infarction $(p<0.001)$, or tobacco use $(p=0.002)$. Patients with non-ischemic HF were younger (mean $=63.3$ vs. 71.1 years; $\mathrm{p}<0.001$ ) than those who had ischemic HF. Patients with ischemic HF were more likely to have been given beta-blockers ( $96.9 \%$ vs. $85.1 \%$ of patients with non-ischemic HF; $\mathrm{p}=0.001$ ).

\begin{tabular}{|c|c|c|c|}
\hline \multirow{3}{*}{ Characteristic } & \multicolumn{3}{|c|}{ Type of Heart Failure } \\
\hline & $\begin{array}{l}\text { Ischemic } \\
(n=131)\end{array}$ & $\begin{array}{l}\text { Non-Ischemic } \\
\quad(n=141)\end{array}$ & p-value \\
\hline & $\mathrm{N} \quad \%$ & $\mathbf{N} \quad \%$ & \\
\hline Age (years) & & & $<0.001^{\star}$ \\
\hline Mean (SD) & $71.1(8.4)$ & $63.3(12.5)$ & \\
\hline
\end{tabular}




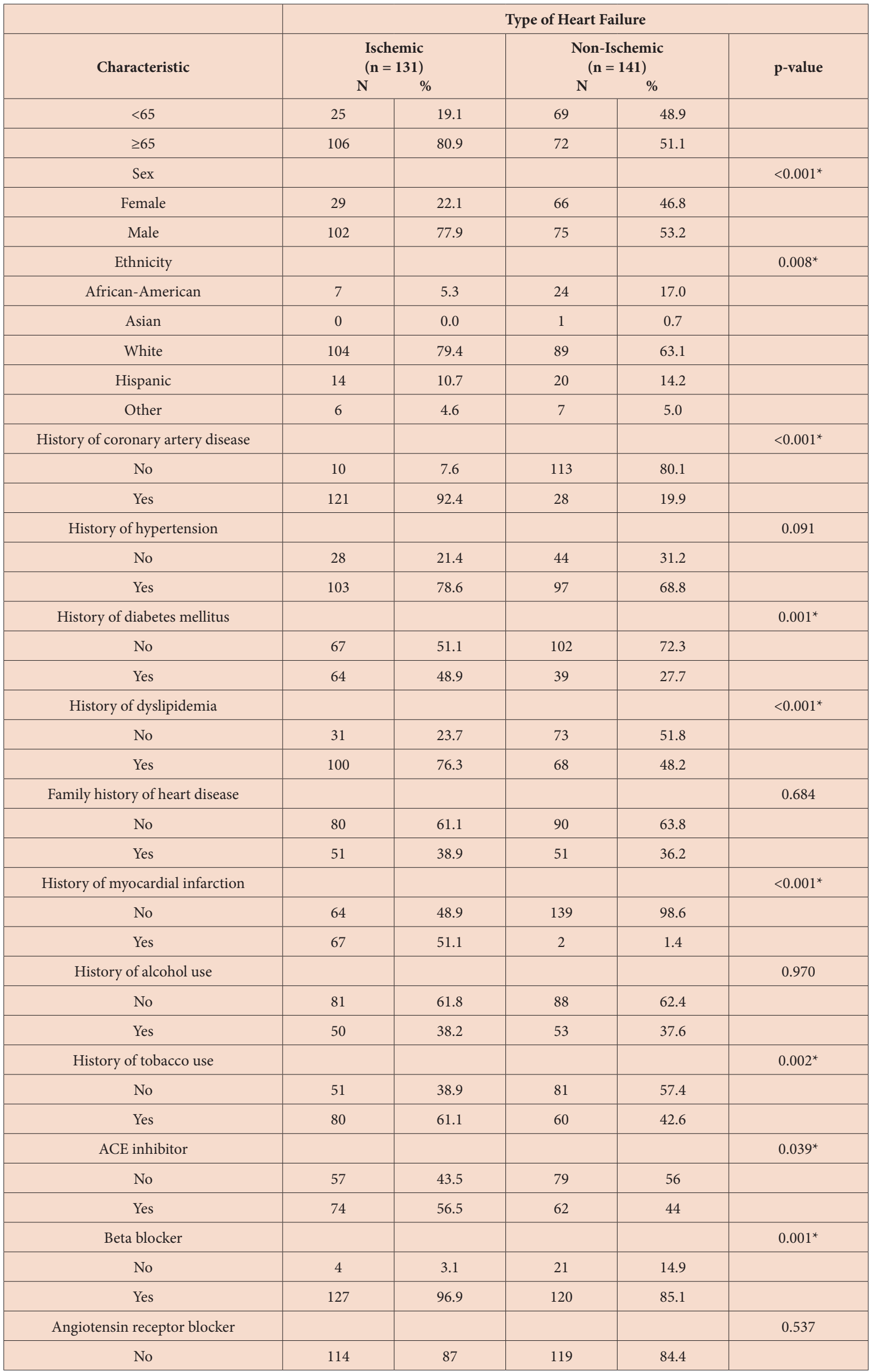




\begin{tabular}{|c|c|c|c|c|c|}
\hline \multirow{3}{*}{ Characteristic } & \multicolumn{5}{|c|}{ Type of Heart Failure } \\
\hline & \multirow{2}{*}{\multicolumn{2}{|c|}{$\begin{array}{l}\text { Ischemic } \\
(\mathrm{n}=131) \\
\mathrm{N} \quad \%\end{array}$}} & \multicolumn{2}{|c|}{$\begin{array}{l}\text { Non-Ischemic } \\
(\mathrm{n}=141)\end{array}$} & \multirow[t]{3}{*}{ p-value } \\
\hline & & & & 6 & \\
\hline Yes & 17 & 13 & 22 & 15.6 & \\
\hline CRT implantation $(\mathrm{N}=58)$ & 27 & 46.6 & 31 & 53.4 & 0.782 \\
\hline Cancer Diagnosis & & & & & 0.059 \\
\hline Liquid tumor (leukemia) & 28 & 21.4 & 42 & 29.8 & \\
\hline $\begin{array}{c}\text { Solid tumor (breast, lung, sarcoma, } \\
\text { lymphoma) }\end{array}$ & 100 & 76.3 & 99 & 70.2 & \\
\hline No Cancer & 3 & 2.3 & 0 & 0.0 & \\
\hline
\end{tabular}

"Significant at $\mathrm{p}<0.05$.

Abbreviations: CRT, cardiac resynchronization therapy; SD, standard deviation.

Table 1: Sociodemographic and Clinical Characteristics of the Study Population (N=272)

Multivariate logistic regression analyses in Table 2 showed that non-ischemic HF was significantly associated with younger age ( $<65$ years) $(\mathrm{OR}=0.91 ; 95 \% \mathrm{CI}=0.87-0.95)$ and female sex $(\mathrm{OR}=2.5 ; 95 \% \mathrm{CI}=1.1-6.0)$. As expected ischemic $\mathrm{HF}$ was significantly associated with a history of myocardial infarction, diabetes and coronary artery disease $(\mathrm{p}<0.001)$.

\begin{tabular}{|c|c|c|c|c|c|}
\hline \multicolumn{2}{|l|}{ Variable } & \multirow{2}{*}{$\begin{array}{c}\text { OR } \\
1.0 \\
0.908\end{array}$} & \multirow{2}{*}{$\begin{array}{c}\begin{array}{c}95 \% \text { CL upper } \\
\text { bound }\end{array} \\
0.867\end{array}$} & \multirow{2}{*}{$\begin{array}{c}\begin{array}{c}95 \% \text { CL lower } \\
\text { bound }\end{array} \\
0.952\end{array}$} & \multirow{2}{*}{$\begin{array}{l}\text { p-value } \\
<0.001^{*}\end{array}$} \\
\hline Age & $\begin{array}{l}\geq 65 \\
<65\end{array}$ & & & & \\
\hline Sex & $\begin{array}{c}\text { Male } \\
\text { Female }\end{array}$ & $\begin{array}{c}1.0 \\
2.523\end{array}$ & 1.067 & 5.968 & $0.035^{*}$ \\
\hline Myocardial infarction & $\begin{array}{l}\text { No } \\
\text { Yes }\end{array}$ & $\begin{array}{c}1.0 \\
0.023\end{array}$ & 0.004 & 0.123 & $<0.001^{\star}$ \\
\hline Coronary artery disease & $\begin{array}{l}\text { No } \\
\text { Yes }\end{array}$ & $\begin{array}{c}1.0 \\
0.052\end{array}$ & 0.022 & 0.124 & $<0.001^{*}$ \\
\hline Diabetes mellitus & $\begin{array}{l}\text { No } \\
\text { Yes }\end{array}$ & $\begin{array}{c}1.0 \\
0.391\end{array}$ & 0.169 & 0.908 & $0.029^{*}$ \\
\hline
\end{tabular}

"Significant at $\mathrm{p}<0.05$.

Abbreviations: CI, confidence limit; OR, odds ratio.

Table 2: Multivariate Model of Chemo-induced Cardiomyopathy (Non-Ischemic HF)

There were no significant differences between the two groups with regard to cardiac risk factors for hypertension ( $\mathrm{p}=0.091$ ), family history of heart disease $(\mathrm{p}=0.684)$, or the use of alcohol $(\mathrm{p}=0.970)$.

\section{CRT Placement versus no CRT Placement}

The characteristics of patients who received CRT placement versus those who did not receive CRT are listed in Table 3. There were no significant differences between the two groups except for the patient's sex $(p=0.036)$ and cancer diagnosis $(p=0.037)$. Patients who received CRT implantation were mostly male $(53.4 \%$ vs. $46.6 \%, \mathrm{p}=0.036)$ and had a solid tumor (lung, breast, sarcoma, lymphoma) versus a liquid tumor (leukemia) $(86.2 \%$ vs $13.8 \%, \mathrm{p}=0.037)$.

\begin{tabular}{|c|c|c|c|c|c|}
\hline & \multicolumn{2}{|c|}{$\begin{array}{c}\text { CRT (No) } \\
\mathbf{n = 2 1 4}\end{array}$} & \multicolumn{2}{c|}{$\begin{array}{c}\text { CRT (Yes) } \\
\mathbf{n}=\mathbf{5 8}\end{array}$} \\
\hline Characteristic & $\mathbf{N}$ & $\mathbf{N}$ & $\mathbf{N}$ & $\mathbf{0}$ & $\mathbf{p}$-value \\
\hline Age (years) & & & & & 0.766 \\
\hline$<65$ & 73 & 34.1 & 21 & 36.2 & \\
\hline$\geq 65$ & 141 & 65.9 & 37 & 63.8 & \\
\hline Sex & & & & & $0.036^{*}$ \\
\hline Female & 68 & 31.8 & 27 & 46.6 & \\
\hline Male & 146 & 68.2 & 31 & 53.4 & \\
\hline Ethnicity & & & & & 0.114 \\
\hline African-American & 21 & 9.8 & 10 & 17.2 & \\
\hline Asian & 1 & 0.5 & 0 & 0.0 & \\
\hline Caucasian & 157 & 73.4 & 36 & 62.1 & \\
\hline
\end{tabular}




\begin{tabular}{|c|c|c|c|c|c|}
\hline \multirow[b]{2}{*}{ Characteristic } & \multicolumn{2}{|c|}{$\begin{array}{c}\text { CRT (No) } \\
\mathrm{n}=214\end{array}$} & \multicolumn{2}{|c|}{$\begin{array}{l}\text { CRT (Yes) } \\
\mathrm{n}=\mathbf{5 8}\end{array}$} & \multirow[b]{2}{*}{ p-value } \\
\hline & $\mathbf{N}$ & $\%$ & $\mathbf{N}$ & $\%$ & \\
\hline Hispanic & 23 & 10.7 & 11 & 19.0 & \\
\hline Other & 12 & 5.6 & 1 & 1.7 & \\
\hline $\begin{array}{l}\text { History of coronary artery } \\
\text { disease }\end{array}$ & & & & & 0.156 \\
\hline No & 92 & 43.0 & 31 & 53.4 & \\
\hline Yes & 122 & 57.0 & 27 & 46.6 & \\
\hline History of hypertension & & & & & 0.374 \\
\hline No & 54 & 25.2 & 18 & 31.0 & \\
\hline Yes & 160 & 74.8 & 40 & 69.0 & \\
\hline History of diabetes mellitus & & & & & 0.218 \\
\hline No & 137 & 64.0 & 32 & 55.2 & \\
\hline Yes & 77 & 36.0 & 26 & 44.8 & \\
\hline $\begin{array}{l}\text { Family history of heart } \\
\text { disease }\end{array}$ & & & & & 0.320 \\
\hline No & 137 & 64.0 & 33 & 56.9 & \\
\hline Yes & 77 & 36.0 & 25 & 43.1 & \\
\hline History of dyslipidemia & & & & & 0.720 \\
\hline No & 83 & 38.8 & 21 & 36.2 & \\
\hline Yes & 131 & 61.2 & 37 & 63.8 & \\
\hline $\begin{array}{l}\text { History of myocardial } \\
\text { infarction }\end{array}$ & & & & & 0.922 \\
\hline No & 160 & 74.8 & 43 & 74.1 & \\
\hline Yes & 54 & 25.2 & 15 & 25.9 & \\
\hline History of alcohol use & & & & & 0.769 \\
\hline No & 132 & 61.7 & 37 & 63.8 & \\
\hline Yes & 82 & 38.3 & 21 & 36.2 & \\
\hline History of tobacco use & & & & & 0.351 \\
\hline No & 107 & 50.0 & 25 & 43.1 & \\
\hline Yes & 107 & 50.0 & 33 & 56.9 & \\
\hline $\begin{array}{l}\text { Angiotensin converting } \\
\text { enzyme inhibitor (ACEI) }\end{array}$ & & & & & 1.000 \\
\hline No & 107 & 50.0 & 29 & 50.0 & \\
\hline Yes & 107 & 50.0 & 29 & 50.0 & \\
\hline Beta-blocker & & & & & 0.310 \\
\hline No & 22 & 10.3 & 3 & 5.2 & \\
\hline Yes & 192 & 89.7 & 55 & 94.8 & \\
\hline $\begin{array}{l}\text { Angiotensin receptor } \\
\text { blocker }\end{array}$ & & & & & 0.477 \\
\hline No & 185 & 86.4 & 48 & 82.8 & \\
\hline Yes & 29 & 13.6 & 10 & 17.2 & \\
\hline Cancer diagnosis & & & & & $0.037^{*}$ \\
\hline Liquid tumor (leukemia) & 62 & 29.0 & 8 & 13.8 & \\
\hline $\begin{array}{l}\text { Solid tumor (breast, lung, } \\
\text { sarcoma, lymphoma) }\end{array}$ & 149 & 69.6 & 50 & 86.2 & \\
\hline No cancer & 3 & 1.4 & 0 & 0.0 & \\
\hline
\end{tabular}

"Significant at $\mathrm{p}<0.05$.

Abbreviation: CRT, cardiac resynchronization therapy.

Table 3: Characteristics of Patients With and Without CRT Placement 


\section{Discussion}

In 2001, CRT was approved by the US Food and Drug Administration for use in selected patients with left ventricular dysfunction. This included patients with moderate to severe HF (New York Heart Association functional class III to IV), with an LVEF of $\leq 35 \%$, and QRS duration $\geq 120 \mathrm{~ms}$ despite optimal pharmacotherapy. The use of CRT was associated with survival benefit, left ventricular reverse remodeling, and reduced hospitalizations for patients with HF [25-27]. The primary finding in this study is that only a limited number of eligible cancer patients with HF received the device. To our knowledge, this is the first study to report on CRT utilization in cancer patients with HF.

HF in the general population typically is secondary to myocardial infarction, coronary artery disease, or hypertension [28]. Our results indicated that the patients with cancer in our sample were similar to patients in the general HF population, in terms of demographic characteristics and comorbidities (specifically, hypertension, hyperlipidemia, and coronary artery disease). It is imperative that cardiac risk factors be managed aggressively in patients with cancer to prevent development of HF. Moreover, patients in this cohort were on optimum HF medications including beta-blockers (90.8\%) and ACEIs (50.0\%) which are known to promote reverse ventricular remodelling and improvement in ejection fraction [29-31]. Clinical practice guidelines recommend CRT for appropriate patients who remain symptomatic despite optimal pharmacological therapy [28,32-34].

However, 10 (7.6\%) patients with ischemic HF in this cohort had no known history of coronary artery disease. This can be explained by the fact that in patients with cancer, there are concomitant disease conditions that can result in ischemic cardiomyopathy in the absence of coronary artery disease. Ischemic cardiomyopathy can occur in embolic conditions (e.g., atrial fibrillation, endocarditis, thrombophilic states) and microvascular ischemia resulting from infiltrative myocardial disease (e.g., cardiac amyloidosis, hemochromatosis, and sarcoidosis), which are commonly seen in patients with cancer [35-39].

Cardiac amyloidosis is caused by tissue deposition of misfolded proteins that results in progressive organ damage [39]. The deposition is most common in the myocardium, causing the myocardium to become thick with a rubbery consistency [39]. Highgrade infiltration $(>50 \%$ ) of the myocardium is most common in the immunoglobulin light-chain amyloidosis variety, and $90 \%$ of cases have microvascular involvement, resulting in tissue ischemia and infarction [38,40]. Resultant myocardial fibrosis adds to the myocardial dysfunction, causing heart failure and cardiac arrhythmias.

Although the specific etiology of left ventricular dysfunction leading to HF in this patient cohort was difficult to ascertain, we found that $51.8 \%$ had HF with non-ischemic etiology. Non-ischemic HF can be caused by cancer therapies, infection, valvular disease, excessive alcohol use, and myocarditis. Indeed, in our multivariate model, we found that younger age and female sex were significantly associated with non-ischemic HF and that ischemic HF was significantly associated with a history of myocardial infarction, diabetes, and cardiovascular disease. Regardless of etiology, these patients were on optimum medical therapy as recommended by clinical guidelines; $90.8 \%(n=247)$ were taking beta-blockers, which are believed to have a cardio-protective benefit as a consequence of their potent antioxidant effects, modulation of neurohumoral factors, and modulation of cardiac electrophysiological properties [41]. This is significant because, despite receiving appropriate pharmacotherapy, all of the patients in our sample were eligible for CRT on the basis of LVEF and QRS parameters, yet more than three quarters of them had not received it at the time of their participation in the study. Adding CRT to optimal pharmacotherapy could be an effective approach for managing $\mathrm{HF}$ in patients with cancer and warrants further exploration in this growing patient population.

We reviewed data from July 01, 2010 to June 30, 2012. In 2012, the American College of Cardiology Foundation/American Heart Association/Heart Rhythm Society guidelines expanded the CRT indication to include patients with milder symptoms, for example, LVEF $\leq 30 \%$, left bundle-branch block pattern, and QRS duration of $>150 \mathrm{~ms}[26,42]$. However, our inclusion criteria were based on the earlier guidelines that were available when we conducted the study. Consequently, with the expanded guidelines, even more cancer patients may be eligible for CRT than we observed in this study.

\section{Limitations}

There are limitations to this study. First, this is a retrospective study of a small patient sample in a tertiary cancer center and not fully representative of cancer patients with HF in general hospitals and community cancer centers. Data were abstracted from patient medical records by more than one person, which could have affected the accuracy, consistency, or completeness of the information extracted. It is possible that patients who appeared to be eligible for CRT in this study according to cancer diagnosis or treatment may have had other contraindications that were not reviewed. Nonetheless, we specifically manage patients with cancer in our cardiac practice; other practices with different patient populations or care patterns may not encounter this issue. In addition, because this is a cross-sectional study, the lack of follow-up data precludes assessment of benefit of CRT in improving health outcomes and whether a CRT device was subsequently implanted in eligible patients.

\section{Conclusions}

CRT is underutilized in cancer patients with HF. The findings from this study may provide preliminary information to assist in the development of a protocol that will identify cancer patients who may benefit from CRT implantation. Chemotherapy-induced cardiomyopathy, a most common cause of non-ischemic heart failure, will be an increasing clinical issue in cancer patients. When 
HF has a non-ischemic etiology secondary to chemotherapy, CRT may be less utilized due to shortened life expectancy, yet some evidence suggests that CRT has beneficial effects on morbidity, mortality, and left ventricular function in patients with nonischemic cardiomyopathy. Future prospective studies with larger sample sizes are needed.

\section{Financial support}

This study was supported by a grant to Anecita P. Fadol from the Medtronic CRDM External Research Program, and by the MD Anderson Cancer Center Support Grant (NIH/NCI award number P30 CA016672) for use of the Clinical Trials Support Resource. The content is solely the responsibility of the authors and does not necessarily represent the official views of the National Cancer Institute or the National Institutes of Health. The sponsors played no role in the design of the study; in the collection, analysis and interpretation of data; in the writing of the report; or in the decision to submit the article for publication.

Relationships with industry and other entities: Anecita P. Fadol received research grant funding from Medtronic for the conduct of this study. Medtronic manufactures a CRT device. The authors declare that they have no other relationships to disclose.

\section{Acknowledgement}

The authors acknowledge Jeanie F. Woodruff, BS, ELS for editorial assistance and Valerie Shelton, BS and Lisa A. Smith, RN for their assistance with data collection.

\section{References}

1. Anand IS, Carson P, Galle E, Song R, Boehmer J, et al. (2009) Cardiac resynchronization therapy reduces the risk of hospitalizations in patients with advanced heart failure: results from the Comparison of Medical Therapy, Pacing and Defibrillation in Heart Failure (COMPANION) trial. Circulation 119: 969-77.

2. Kamioka M, Suzuki H, Yamada S, Kamiyama Y, Saitoh S, et al. (2012) High sensitivity C-reactive protein predicts nonresponders and cardiac deaths in severe heart failure patients after CRT implantation. Int Heart J 53: 306-12.

3. Linde C, Abraham WT, Gold MR, St John Sutton M, Ghio S, et al. (2008) Randomized trial of cardiac resynchronization in mildly symptomatic heart failure patients and in asymptomatic patients with left ventricular dysfunction and previous heart failure symptoms. J Am Coll Cardiol 52: 1834-43.

4. McAlister FA, Ezekowitz J, Hooton N, Vandermeer B, Spooner C, et al. (2007) Cardiac resynchronization therapy for patients with left ventricular systolic dysfunction: a systematic review. JAMA 297: 2502-14.

5. Young JB, Abraham WT, Smith AL, Leon AR, Lieberman R, et al. (2003) Combined cardiac resynchronization and implantable cardioversion defibrillation in advanced chronic heart failure: the MIRACLE ICD Trial. JAMA 289: 2685-94.

6. Baker CM, Christopher TJ, Smith PF, Langberg JJ, Delurgio DB, et al. (2002) Addition of a left ventricular lead to conventional pacing systems in patients with congestive heart failure: feasibility, safety, and early results in 60 consecutive patients. Pacing Clin Electrophysiol 25: 1166-71.

7. Chen J, Long JB, Hurria A, Owusu C, Steingart RM, et al. (2012) Incidence of heart failure or cardiomyopathy after adjuvant trastuzumab therapy for breast cancer. J Am Coll Cardiol 60: 2504-12.

8. Chen MH, Colan SD, Diller L (2011) Cardiovascular disease: cause of morbidity and mortality in adult survivors of childhood cancers. Circ Res 108: 619-28.

9. Eschenhagen T, Force T, Ewer MS, de Keulenaer GW, Suter TM, et al. (2011) Cardiovascular side effects of cancer therapies: a position statement from the Heart Failure Association of the European Society of Cardiology. Eur J Heart Fail 13: 1-10.

10. Force T, Kerkela R (2008) Cardiotoxicity of the new cancer therapeutics--mechanisms of, and approaches to, the problem. Drug Discov Today 13: 778-84.

11. Ky B, Vejpongsa P, Yeh ET, Force T, Moslehi JJ (2013) Emerging paradigms in cardiomyopathies associated with cancer therapies. Circ Res 113: 754-64.

12. Jones LW, Haykowsky M, Peddle CJ et al. (2007) Cardiovascular risk profile of patients with HER2/neu-positive breast cancer treated with anthracycline-taxanecontaining adjuvant chemotherapy and/or trastuzumab. Cancer Epidemiol Biomarkers Prev 16: 1026-31.

13. Jones LW, Haykowsky MJ, Swartz JJ, Douglas PS, et al. (2007) Early breast cancer therapy and cardiovascular injury. J Am Coll Cardiol 50: 1435-41.

14. Lenihan DJ, Oliva S, Chow EJ, Cardinale D (2013) Cardiac toxicity in cancer survivors. Cancer 119: 2131-42.

15. Swain SM, Whaley FS, Ewer MS (2003) Congestive heart failure in patients treated with doxorubicin: a retrospective analysis of three trials. Cancer 97: 2869-79. 16. Von Hoff DD, Layard MW, Basa P, Davis HL Jr, Von Hoff AL, et al. (1979) Risk factors for doxorubicin-induced congestive heart failure. Ann Intern Med 91: 710-7.

17. Slamon D, Eiermann W, Robert N, Pienkowski T, Martin M, et al. (2011) Adjuvant trastuzumab in HER2-positive breast cancer. N Engl J Med 365: $1273-83$.

18. Bowles EJ, Wellman R, Feigelson HS, Onitilo AA, Freedman AN, et al. (2012) Risk of heart failure in breast cancer patients after anthracycline and trastuzumab treatment: a retrospective cohort study. J Natl Cancer Inst 104: 1293-305.

19. Slamon DJ, Leyland-Jones B, Shak S, Fuchs H, Paton V, et al. (2001) Use of chemotherapy plus a monoclonal antibody against HER2 for metastatic breast cancer that overexpresses HER2. N Engl J Med 344: 783-92.

20. Maurea N, Coppola C, Ragone G, Frasci G, Bonelli A, et al. (2010) Women survive breast cancer but fall victim to heart failure: the shadows and lights of targeted therapy. J Cardiovasc Med (Hagerstown) 11: 861-8.

21. Viani GA, Afonso SL, Stefano EJ, De Fendi LI, Soares FV (2007) Adjuvant trastuzumab in the treatment of her-2-positive early breast cancer: a meta-analysis of published randomized trials. BMC cancer 7: 153.

22. Yeh ET, Bickford CL (2009) Cardiovascular complications of cancer therapy: incidence, pathogenesis, diagnosis, and management. J Am Coll Cardiol 53: 223147.

23. Howlader N, Ries LA, Mariotto AB, Reichman ME, Ruhl J, et al. (2010) Improved estimates of cancer-specific survival rates from population-based data. J Natl Cancer Inst 102: 1584-98.

24. Chu TF, Rupnick MA, Kerkela R, Dallabrida SM, Zurakowski D, et al. (2007) Cardiotoxicity associated with tyrosine kinase inhibitor sunitinib. Lancet 370: 2011-9. 
25. Goldenberg I, Hall WJ, Beck CA, Moss AJ, Barsheshet A, et al. (2011) Reduction of the risk of recurring heart failure events with cardiac resynchronization therapy: MADIT-CRT (Multicenter Automatic Defibrillator Implantation Trial With Cardiac Resynchronization Therapy). J Am Coll Cardiol 58 : $729-37$.

26. Tracy CM, Epstein AE, Darbar D, DiMarco JP, Dunbar SB, et al. (2012) 2012 ACCF/AHA/HRS focused update of the 2008 guidelines for device-based therapy of cardiac rhythm abnormalities: a report of the American College of Cardiology Foundation/American Heart Association Task Force on Practice Guidelines and the Heart Rhythm Society. [corrected]. Circulation 126: 1784-800.

27. Yancy CW, Jessup M, Bozkurt B, Butler J, Casey DE Jr, et al. (2013) 2013 ACCF/AHA guideline for the management of heart failure: a report of the American College of Cardiology Foundation/American Heart Association Task Force on Practice Guidelines. J Am Coll Cardiol. 62: e147-239.

28. Hunt SA, Abraham WT, Chin MH, Feldman AM, Francis GS, et al. (2009) 2009 focused update incorporated into the ACC/AHA 2005 Guidelines for the Diagnosis and Management of Heart Failure in Adults: a report of the American College of Cardiology Foundation/American Heart Association Task Force on Practice Guidelines: developed in collaboration with the International Society for Heart and Lung Transplantation. Circulation 119: e391-479.

29. Pfeffer MA, Braunwald E, Moye LA, Basta L, Brown EJ Jr, et al. (1992) Effect of captopril on mortality and morbidity in patients with left ventricular dysfunction after myocardial infarction. Results of the survival and ventricular enlargement trial. The SAVE Investigators. N Engl J Med 327: 669-77.

30. Konstam MA, Patten RD, Thomas I, Ramahi T, La Bresh K, et al. (2000) Effects of losartan and captopril on left ventricular volumes in elderly patients with heart failure: results of the ELITE ventricular function substudy. Am Heart J 139: 1081-7.

31. Merlo M, Stolfo D, Anzini M, Francesco N, Bruno P, et al. (2015) Persistent recovery of normal left ventricular function and dimension in idiopathic dilated cardiomyopathy during long-term follow-up: does real healing exist? J Am Heart Assoc 4: e001504.

32. Dickstein K, Vardas PE, Auricchio A, Daubert JC, Linde C, et al. (2010) 2010 Focused Update of ESC Guidelines on device therapy in heart failure: an update of the 2008 ESC Guidelines for the diagnosis and treatment of acute and chronic heart failure and the 2007 ESC guidelines for cardiac and resynchronization therapy. Developed with the special contribution of the Heart Failure Association and the European Heart Rhythm Association. Eur Heart J 31 : $2677-87$.

33. Heart Failure Society of A, Lindenfeld J, Albert NM, Collins SP, et al. (2010) HFSA 2010 Comprehensive Heart Failure Practice Guideline. J Card Fail 16: e1-194. 34. Lindenfeld J, Albert NM, Boehmer JP, Collins SP, Ezekowitz JA, et al. (2010) HFSA 2010 Comprehensive Heart Failure Practice Guideline. J Card Fail 16: e1-194. 35. Felker GM, Thompson RE, Hare JM, Hruban RH, Clemetson DE, et al. (2000) Underlying causes and long-term survival in patients with initially unexplained cardiomyopathy. N Engl J Med 342: 1077-84.

36. Cooper LT Jr. (2009) Myocarditis. N Engl J Med 360: 1526-38.

37. Richardson P, McKenna W, Bristow M, Maisch B, Mautner B, et al. (1996) Report of the 1995 World Health Organization/International Society and Federation of Cardiology Task Force on the Definition and Classification of cardiomyopathies. Circulation 93: 841-2.

38. Smith RR, Hutchins GM (1979) Ischemic heart disease secondary to amyloidosis of intramyocardial arteries. Am J Cardiol 44: 413-7.

39. Merlini G, Seldin DC, Gertz MA (2011) Amyloidosis: pathogenesis and new therapeutic options. J Clin Oncol 29: $1924-33$.

40. Arbustini E, Merlini G, Gavazzi A, Grasso M, Diegoli M, et al. (1995) Cardiac immunocyte-derived (AL) amyloidosis: an endomyocardial biopsy study in 11 patients. Am Heart J 130: 528-36.

41. Cheng J, Kamiya K, Kodama I (2001) Carvedilol: molecular and cellular basis for its multifaceted therapeutic potential. Cardiovasc Drug Rev 19: 152-71.

42. Wann LS, Curtis AB, January CT, Ellenbogen KA, Lowe JE, et al. (2011) 2011 ACCF/AHA/HRS focused update on the management of patients with atrial fibrillation (Updating the 2006 Guideline): a report of the American College of Cardiology Foundation/American Heart Association Task Force on Practice Guidelines. J Am Coll Cardiol 57: 223-42.

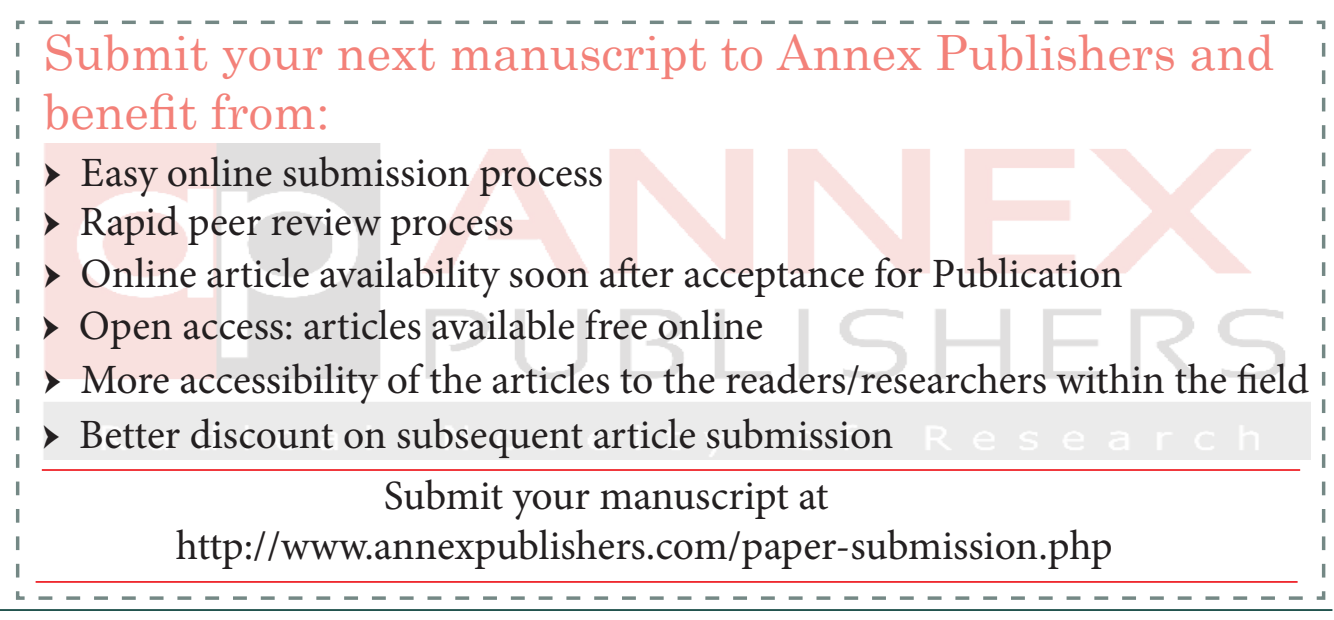

